\title{
Improvement the Activity and Selectivity of Fenton System in the Oxidation of Alcohols
}

\author{
Guoqiang Yang, Qiuxing Lin, Xingbang Hu, Youting Wu, and Zhibing Zhang \\ School of Chemistry and Chemical Engineering and National Engineering Research Center for Organic Pollution Control and Resource, \\ Nanjing University, Nanjing 210093, China \\ Correspondence should be addressed to Xingbang Hu; huxb@nju.edu.cn and Youting Wu; ytwu@nju.edu.cn
}

Received 18 October 2013; Accepted 23 February 2014; Published 24 March 2014

Academic Editor: David W. Mazyck

Copyright (c) 2014 Guoqiang Yang et al. This is an open access article distributed under the Creative Commons Attribution License, which permits unrestricted use, distribution, and reproduction in any medium, provided the original work is properly cited.

The reactivity and selectivity of Fenton system $\left(\mathrm{Fe}^{2+} / \mathrm{H}_{2} \mathrm{O}_{2}\right)$ were improved with N-hydroxyphthalimide (NHPI) as cocatalyst. The oxidation process of benzyl alcohol to benzaldehyde has been studied. The reaction catalyzed by this new $\mathrm{Fe}^{2+} / \mathrm{H}_{2} \mathrm{O}_{2} / \mathrm{NHPI}$ system can be well performed under room temperature without adding any organic solvent. Besides, this catalyst system is effective for the oxidation of different alcohols.

\section{Introduction}

The Fenton reagent is a simple catalyst system which is composed of $\mathrm{Fe}^{2+}$ and $\mathrm{H}_{2} \mathrm{O}_{2}$. In the reaction process with Fenton's reagent, the hydroxyl radicals are generated rapidly at the presence of ferrous ion. This catalyst system is proved to be successful for the treatment of organic pollutants in industrial wastewater [1-12]. There are numerous reports concerning pretreatment option to improve the biodegradability of complex wastes and recalcitrant from industry wastewater and landfill leachate [2-4]. The original pollutants are often transformed to $\mathrm{CO}_{2}$ and $\mathrm{H}_{2} \mathrm{O}$ due to the strong oxidizing property of the Fenton system [4-7]. In recent studies, Fenton system is coupled with other methods, such as membrane filtration and coagulation, to degrade organic compounds to a larger extent $[8,9]$. Besides, the Fenton reagent is also effective in light alcohols and alkane's oxyfunctionalization [10, 13], but the application for selective oxidation is rare $[11,12]$.

The Fenton system has wonderful water solubility and there are abundant ferrous irons on the earth. Thus, it is possible to develop a mild and inexpensive water phase oxidation process using this system. Despite its numerous advantages, one limitation of traditional Fenton's reagent must be taken into account: its high oxygen reactivity, which often leads to deep oxidation $[5,6,14-16]$. To apply the Fenton system in chemical synthesis, the most crucial problem is how to control its reactivity and enhance its selectivity. The efficiency of Fenton's reagent is affected by various factors, such as $\mathrm{pH}$, the counterion of $\mathrm{Fe}^{2+}$, solvent, iron chelation, UV, and microwaves, which control the oxidation reactivity and regeneration ability of $\mathrm{Fe}^{2+}$ from $\mathrm{Fe}^{3+}[4,17-20]$. In addition, it has been found that the additives play a vital role to change the reactivity of Fenton system [13, 21-23]. For example, the reaction with $\mathrm{KH}_{2} \mathrm{PO}_{4}$ as additive provided high conversion and good selectivity in the oxidation of benzyl alcohol [13].

The objective of this study is to control the reactivity of Fenton system and enhance its selectivity. Based on a detailed investigation on a series of additives, we have found that the reactivity of Fenton system can be well controlled and the benzyl alcohol oxidation can be performed with good selectivity at room temperature in water.

\section{Experimental}

All the chemicals were obtained with purities higher than 99\%. A typical experiment was carried out in a water bath. The alcohol $(20 \mathrm{mmol}), \mathrm{FeSO}_{4} \cdot 7 \mathrm{H}_{2} \mathrm{O}(0.5 \mathrm{mmol})$, and NHPI $(0.5 \mathrm{mmol})$ were added to a glass reactor. $44 \mathrm{mmol} \mathrm{H}_{2} \mathrm{O}_{2}$ (30 wt $\%$ in water, $4.5 \mathrm{~mL}$ ) was added with a syringe pump by $0.2 \mathrm{~mL} / \mathrm{min}$ speed in $30 \mathrm{~min}$. The reaction mixture was vigorously stirred (about $750 \mathrm{rpm}$ ). Reaction mixtures were analyzed using GC and GC-MS. 
TABLE 1: Effect of additives for the oxidation of benzyl alcohol to benzaldehyde at $70^{\circ} \mathrm{C}^{\mathrm{a}}$.

\begin{tabular}{lcccc}
\hline Entry & Catalyst & Amount $^{\mathrm{b}}(\mathrm{mol} \%)$ & Conv. $(\%)$ & \multicolumn{1}{c}{ Sel. ${ }^{\mathrm{c}}(\%)$} \\
\hline 1 & $\mathrm{FeSO}_{4} / \mathrm{NaBF}_{4}$ & $2.5 \% / 1 \%$ & 66.6 & $94.5(89: 11)$ \\
2 & & $2.5 \% / 10 \%$ & 71.0 & $94.3(88: 12)$ \\
3 & & $2.5 \% / 1 \%$ & 2.0 & $96.0(87: 13)$ \\
4 & $\mathrm{FeSO}_{4} / \mathrm{NaH}_{2} \mathrm{PO}_{4}$ & $2.5 \% / 5 \%$ & 1.6 & $96.5(87: 13)$ \\
5 & & $2.5 \% / 10 \%$ & 64.1 & $93.3(93: 7)$ \\
6 & & $2.5 \% / 1 \%$ & 4.4 & $95.9(90: 10)$ \\
7 & $\mathrm{FeSO}_{4} / \mathrm{KH}_{2} \mathrm{PO}_{4}$ & $2.5 \% / 2.5 \%$ & 1.9 & $95.1(92: 8)$ \\
8 & & $2.5 \% / 5 \%$ & 51.3 & $89.2(88: 12)$ \\
9 & & $2.5 \% / 1 \%$ & 32.8 & $94.7(82: 18)$ \\
10 & $\mathrm{FeSO}_{4} / \mathrm{KHP}^{\mathrm{d}}$ & $2.5 \% / 2.5 \%$ & $86.7(92: 8)$ \\
\hline
\end{tabular}

${ }^{\mathrm{a}} 20 \mathrm{mmol}$ of benzyl alcohol (2.16 g), 2.2 equiv. of $\mathrm{H}_{2} \mathrm{O}_{2}\left(44 \mathrm{mmol}, 4.5 \mathrm{~mL}, 30 \mathrm{wt} \%\right.$ in water), reaction time: $0.5 \mathrm{~h}$. $\mathrm{H}_{2} \mathrm{O}_{2}$ was added with a syringe pump by $0.2 \mathrm{~mL} / \mathrm{min}$ speed. ${ }^{\mathrm{b}}$ Amount of catalyst. ${ }^{\mathrm{c}}$ Total selectivity to benzaldehyde and benzoic acid. Value in parentheses means the ratio of benzaldehyde/benzoic acid. ${ }^{\mathrm{d}}$ KHP: potassium hydrogen phthalate.

TABLE 2: Effect of additives for the oxidation of benzyl alcohol to benzaldehyde at $25^{\circ} \mathrm{C}^{\mathrm{a}}$.

\begin{tabular}{|c|c|c|c|c|c|}
\hline Entry & Catalyst & Amount $^{\mathrm{b}}(\mathrm{mol} \%)$ & Time $(\mathrm{h})$ & Conv. (\%) & Sel. $^{\mathrm{c}}(\%)$ \\
\hline 1 & \multirow{3}{*}{$\mathrm{FeSO}_{4} / \mathrm{NaH}_{2} \mathrm{PO}_{4}$} & \multirow{3}{*}{$2.5 \% / 1 \%$} & 0.5 & 3.8 & $95.9(91: 9)$ \\
\hline 2 & & & 2 & 8.6 & $95.1(90: 10)$ \\
\hline 3 & & & 4 & 9.5 & $91.2(90: 10)$ \\
\hline 4 & \multirow{2}{*}{$\mathrm{FeSO}_{4} / \mathrm{NaH}_{2} \mathrm{PO}_{4}$} & \multirow{2}{*}{$2.5 \% / 2.5 \%$} & 0.5 & 1.1 & $98.2(92: 8)$ \\
\hline 5 & & & 2 & 1.9 & $98.2(93: 7)$ \\
\hline 6 & \multirow{2}{*}{$\mathrm{FeSO}_{4} / \mathrm{NaH}_{2} \mathrm{PO}_{4}$} & \multirow{2}{*}{$2.5 \% / 10 \%$} & 0.5 & 1.1 & $98.8(92: 8)$ \\
\hline 7 & & & 19 & 1.3 & $98.9(91: 9)$ \\
\hline 8 & $\mathrm{FeSO}_{4} / \mathrm{KBr}$ & $2.5 \% / 10 \%$ & 0.5 & 3.4 & $100(89: 11)$ \\
\hline 9 & $\mathrm{FeSO}_{4} / \mathrm{NaBF}_{4}$ & $2.5 \% / 10 \%$ & 0.5 & 1.7 & $>99.9(100: 0)$ \\
\hline 10 & $\mathrm{FeSO}_{4} / \mathrm{KH}_{2} \mathrm{PO}_{4}$ & $2.5 \% / 2.5 \%$ & 0.5 & 1.2 & $98.3(93: 7)$ \\
\hline 11 & $\mathrm{FeSO}_{4} / \mathrm{N}_{1111}$ Gly & $2.5 \% / 2.5 \%$ & 0.5 & 20.6 & $91.7(96: 4)$ \\
\hline 12 & $\mathrm{FeSO}_{4} / \mathrm{N}_{2111} \mathrm{OAc}$ & $2.5 \% / 2.5 \%$ & 0.5 & 25.7 & $98.4(87: 13)$ \\
\hline 13 & $\mathrm{FeSO}_{4} /[\mathrm{HMIM}]\left[\mathrm{HSO}_{4}\right]$ & $2.5 \% / 10 \%$ & 0.5 & 1.3 & $>99.9(100: 0)$ \\
\hline
\end{tabular}

${ }^{a} 20 \mathrm{mmol}$ of benzyl alcohol, 2.2 equiv. of $\mathrm{H}_{2} \mathrm{O}_{2}$ (30 wt\% in water). $\mathrm{H}_{2} \mathrm{O}_{2}$ was added with a syringe pump by $0.2 \mathrm{~mL} / \mathrm{min}$ speed. ${ }^{\mathrm{b}}$ Amount of catalyst. ${ }^{c}$ Total selectivity to benzaldehyde and benzoic acid. Value in parentheses means the ratio of benzaldehyde/benzoic acid.

Different reaction conditions (temperature, concentration, Fe salt, and speed of adding $\mathrm{H}_{2} \mathrm{O}_{2}$ ) have been optimized. Limited by the length, these results were listed in the Supplementary data (Figures S1 and S2 and Tables S1-S2) (see Supplementary Material available online at http://dx.doi.org/10.1155/2014/823054).

\section{Results and Discussion}

3.1. The Influence of Different Additives. It has been revealed that some additives (such as $\mathrm{KH}_{2} \mathrm{PO}_{4}$ and $\mathrm{KHSO}_{4}$ ) to Fenton system can lead to a more effective oxidizing process at $70^{\circ} \mathrm{C}$ [13]. The role of $\mathrm{KH}_{2} \mathrm{PO}_{4}$ was to control the $\mathrm{pH}$ of the solution which can change the rate to generate hydroxyl radicals. As a result, the selectivity of the reaction was enhanced [13]. Encouraged by this idea, we have tried to further improve the reaction by adding different inorganic buffers in Fenton system. The influence of different additives $\left(\mathrm{NaBF}_{4}, \mathrm{NaH}_{2} \mathrm{PO}_{4}, \mathrm{KH}_{2} \mathrm{PO}_{4}\right.$, and $\left.\mathrm{KHP}\right)$ at $70^{\circ} \mathrm{C}$ was studied (Table 1). Our results with $\mathrm{KH}_{2} \mathrm{PO}_{4}$ as additive were very close to those of a previous report [13]. It seems that the adding of $\mathrm{NaBF}_{4}, \mathrm{NaH}_{2} \mathrm{PO}_{4}$, or KHP cannot give better results.
Performing reaction at room temperature is beneficial to save energy and develop safe process. The performance of these inorganic buffers was investigated at $25^{\circ} \mathrm{C}$. Unfortunately, the reactivity of these catalyst systems is quite poor at room temperature (Table 2, entries 1-10). Though good selectivity can be obtained, the conversion is quite low. Increasing reaction time or changing the amount of additive could not improve the results at all.

Though ionic liquids have shown attractive role in improving the reactivity of oxidation system [24-27], it seems that this compound cannot cooperate well with Fenton system (Table 2, entries 11-13). The conversion with [HMIM] $\left[\mathrm{HSO}_{4}\right]$ (hexylmethylimidazole hydrosulfate) as additive is only $1.3 \%$ at $25^{\circ} \mathrm{C}$. Adding $\mathrm{N}_{1111}$ Gly (tetramethylammonium glycinate) or $\mathrm{N}_{2111} \mathrm{OAc}$ (trimethylethylammonium acetate) can accelerate the reaction, but the selectivity is also not so good.

3.2. NHPI/FeSO $\mathrm{S}_{4}$ Oxidation Process. How to improve the selectivity of Fenton system and maintain its reactivity at the same time are a challenge. To solve this problem and find out an excellent additive, the classical free radical mechanism 
TABLE 3: Oxidation of benzyl alcohol with different catalyst systems at $25^{\circ} \mathrm{C}^{\mathrm{a}}$.

\begin{tabular}{lcccr}
\hline Entry & Catalyst & Amount $^{\text {b }}(\mathrm{mol} \%)$ & Conv. (\%) & \multicolumn{1}{c}{ Sel..$^{\mathrm{c}}(\%)$} \\
\hline 1 & & $2.5 \% / 2.5 \%$ & 36.7 & $99.1(94: 6)$ \\
2 & $\mathrm{FeSO}_{4} / \mathrm{NHPI}$ & $2.5 \% / 1.25 \%$ & 36.0 & $98.2(92: 8)$ \\
3 & & $2.5 \% / 5.0 \%$ & 31.8 & $95.9(90: 10)$ \\
4 & $\mathrm{FeSO}_{4} / \mathrm{TEMPO}$ & $2.5 \% / 2.5 \%$ & 20.5 & $98.9(96: 4)$ \\
5 & $\mathrm{FeSO}_{4} / 4-\mathrm{OH}-\mathrm{TEMPO}$ & $2.5 \% / 2.5 \%$ & 13.9 & $99.6(99: 1)$ \\
6 & $\mathrm{Fe}_{2}\left(\mathrm{SO}_{4}\right)_{3} / \mathrm{NHPI}$ & $2.5 \% / 2.5 \%$ & 32.1 & $95.2(87: 13)$ \\
7 & $\mathrm{Fe}\left(\mathrm{NO}_{3}\right)_{3} / \mathrm{NHPI}$ & $2.5 \% / 2.5 \%$ & 59.9 & $94.2(82: 18)$ \\
8 & $\mathrm{FeCl}_{3} / \mathrm{NHPI}$ & $2.5 \% / 2.5 \%$ & 43.3 & $87.6(84: 16)$ \\
\hline
\end{tabular}

${ }^{\mathrm{a}} 20 \mathrm{mmol}$ of benzyl alcohol, 2.2 equiv. of $\mathrm{H}_{2} \mathrm{O}_{2}$ (30 wt\% in water), reaction time: $0.5 \mathrm{~h} . \mathrm{H}_{2} \mathrm{O}_{2}$ was added with a syringe pump by $0.2 \mathrm{~mL} / \mathrm{min}$ speed. ${ }^{\mathrm{b}} \mathrm{Amount}$ of catalyst. ${ }^{c}$ Total selectivity to benzaldehyde and benzoic acid. Value in parentheses means the ratio of benzaldehyde/benzoic acid.

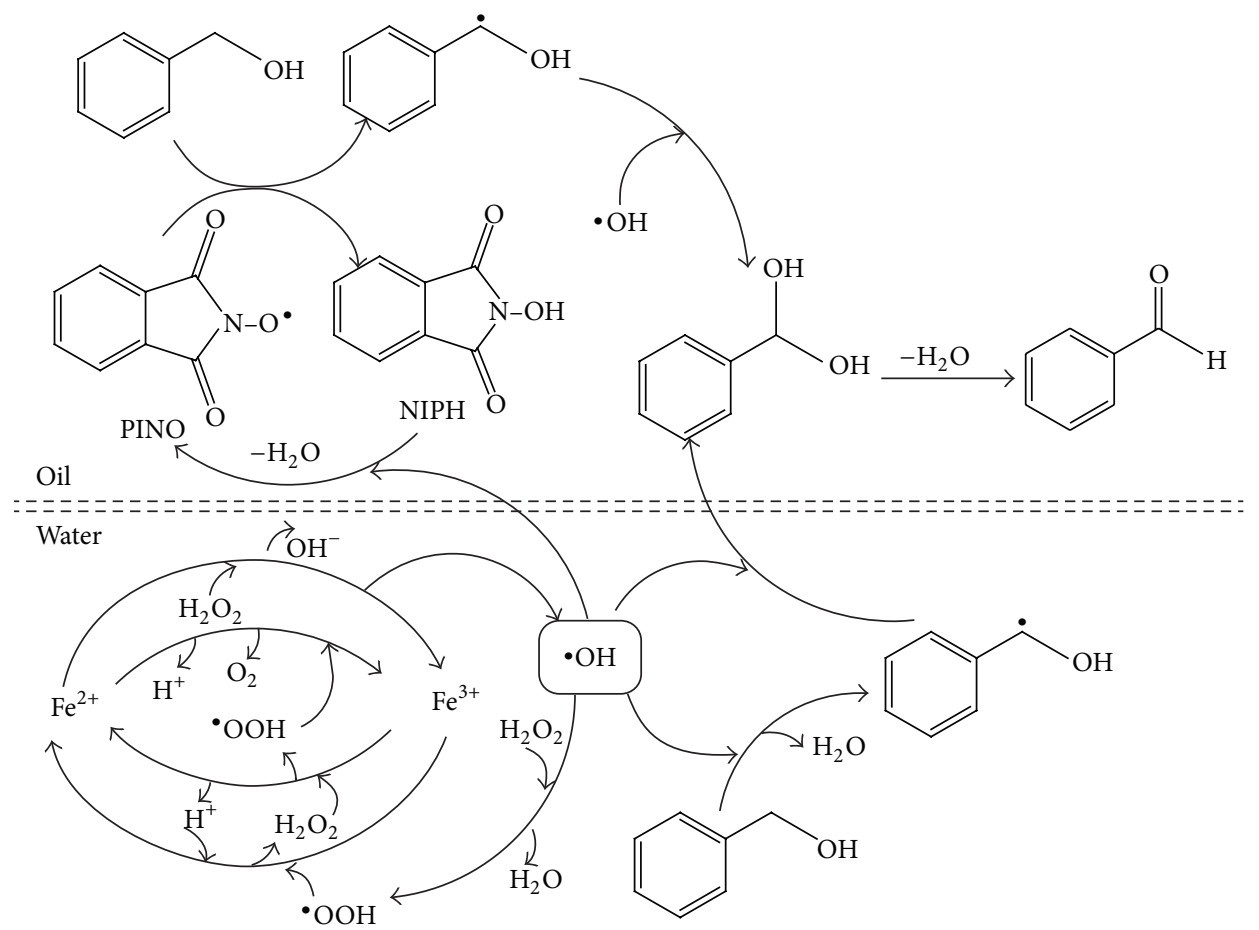

FIGURE 1: Proposed mechanism for the oxidation of benzyl alcohol using NHPI/Fenton system.

of Fenton system was carefully analyzed. The whole radical reaction process of Fenton system is shown as follows [2830]:

$$
\begin{gathered}
\mathrm{Fe}^{2+}+\mathrm{H}_{2} \mathrm{O}_{2} \longrightarrow \mathrm{Fe}^{3+}+\mathrm{OH}^{-}+\mathrm{HO}^{\circ} \\
\mathrm{Fe}^{3+}+\mathrm{H}_{2} \mathrm{O}_{2} \longrightarrow \mathrm{Fe}^{2+}+\mathrm{H}^{+}+\mathrm{HOO}^{\circ} \\
\mathrm{Fe}^{2+}+\mathrm{HO}^{\bullet} \longrightarrow \mathrm{Fe}^{3+}+\mathrm{OH}^{-} \\
\mathrm{H}_{2} \mathrm{O}_{2}+\mathrm{HO}^{\bullet} \longrightarrow \mathrm{H}_{2} \mathrm{O}+\mathrm{HOO}^{\circ} \\
\mathrm{Fe}^{2+}+\mathrm{HOO}^{\bullet} \longrightarrow \mathrm{Fe}^{3+}+\mathrm{OOH}^{-} \\
\mathrm{Fe}^{3+}+\mathrm{HOO}^{\circ} \longrightarrow \mathrm{Fe}^{2+}+\mathrm{H}^{+}+\mathrm{O}_{2}
\end{gathered}
$$

Hydroxyl radical was generated in water phase by a series of complex reactions; then hydroxyl radical can abstract a hydrogen atom from alcohols to form alkyl radicals. If large numbers of hydroxyl radicals accumulate without control, this may cause deep and nonselective oxidation [31]. Therefore, we believed that there should be at least two ways to improve reaction selectivity of Fenton system. One is to control the generation rate of hydroxyl radicals, and the other is to reduce the accumulation of nonselective hydroxyl radicals and convert them to radicals with higher selectivity, such as phthalimide N-oxyl (PINO), which has been widely used in oxidation reaction [32-35]. Adding inorganic buffers can change the $\mathrm{pH}$ of reaction mixture and control the generation rate of radicals. This is the first way mentioned above and it has been widely investigated $[13,18-$ 23]. Selectivity can be enhanced by this way, but the catalytic activity of this system is quite low at room temperature (Table 2). 
TABLE 4: Oxidation of several alcohols ${ }^{\mathrm{a}}$.

\begin{tabular}{|c|c|c|c|c|c|}
\hline Entry & Substrate & Temp. $\left({ }^{\circ} \mathrm{C}\right)$ & Product & Con. (\%) & Sel. (\%) \\
\hline 1 & & 25 & & 36.7 & 93.6 \\
\hline 2 & & 25 & & 4.3 & $>99.9$ \\
\hline 3 & & 25 & & 12.3 & $>99.9$ \\
\hline 4 & & 55 & & 50.5 & $>99.9$ \\
\hline 5 & & 55 & & 4.8 & $>99.9$ \\
\hline 6 & & 55 & & 13.3 & 90.0 \\
\hline 7 & & 55 & & 49.3 & 97.5 \\
\hline 8 & & 55 & & 41.1 & 96.0 \\
\hline 9 & & 55 & & 54.8 & 82.5 \\
\hline
\end{tabular}

${ }^{a}$ Catalyst: $\mathrm{FeSO}_{4} / \mathrm{NHPI}, 20 \mathrm{mmol}$ of benzyl alcohol, 2.2 equiv. of $\mathrm{H}_{2} \mathrm{O}_{2}$ (30 wt $\%$ in water), reaction time: $0.5 \mathrm{~h} . \mathrm{H}_{2} \mathrm{O}_{2}$ was added with a syringe pump by $0.2 \mathrm{~mL} / \mathrm{min}$ speed.

So far, there is no report about the second way. If a method can be developed to achieve the second way, the selectivity should be improved without losing catalytic activity. There are two keys to successfully develop this method: first, the additive should mainly exist in the organic phase, which can avoid possible influence on the Fenton system induced by the additive; second, the additive can react with hydroxyl radicals to generate other radicals with high oxidation selectivity quickly (Figure 1). N-Hydroxyphthalimide (NHPI) is an excellent choice under these two restrictions, and PINO radical can be generated from NHPI, which has been proven to be catalyst with high oxidation selectivity [32-35]. Then, the effect of NHPI as additive was studied. Indeed, the result is satisfying as expected. Both the selectivity and conversion are obviously improved by adding NHPI (Table 3, entries 1 3). TEMPO (2,2,6,6-tetramethylpiperidinooxy) and 4-OHTEMPO (4-hydroxy-TEMPO) also gave better conversion and selectivity comparing with those using inorganic buffers. However, the conversion with TEMPO or 4-OH-TEMPO is lower than that with NHPI. The reactivities of different iron salts were evaluated in the oxidation of benzyl alcohol (Table 3). Obviously, $\mathrm{FeSO}_{4} \cdot 7 \mathrm{H}_{2} \mathrm{O}$ cooperating with NHPI gives the highest selectivity in comparison with $\mathrm{Fe}_{2}\left(\mathrm{SO}_{4}\right)_{3}$, $\mathrm{Fe}\left(\mathrm{NO}_{3}\right)_{3} \cdot 9 \mathrm{H}_{2} \mathrm{O}$, and $\mathrm{FeCl}_{3}$.

3.3. Oxidation of Several Alcohols. To investigate the universality of $\mathrm{NHPI} / \mathrm{FeSO}_{4} / \mathrm{H}_{2} \mathrm{O}_{2}$ system, oxidations of different alcohols were performed (Table 4). Most of these oxidations 
gave good results. Though the result of benzyl alcohol is satisfying at $25^{\circ} \mathrm{C}$, the converting rates of 4-isopropyl benzyl alcohol and $\alpha$-phenylethyl alcohol are a little low at $25^{\circ} \mathrm{C}$, which may be caused by the replacement of electron donating groups. The conversion of $\alpha$-phenylethyl alcohol achieved $50.5 \%$ at $55^{\circ} \mathrm{C}$ with excellent selectivity. It should be noted that ortho substituent and bulky groups may also reduce the reaction rate (Table 4, entries 5 and 6). 4-Methoxybenzyl alcohol and 4-methylbenzyl alcohol were tested at $55^{\circ} \mathrm{C}$ because of the high melting points, and the results were fairly satisfactory (Table 4 , entries $7 \sim 8$ ). However, the selectivity of the 2-butanol oxidation is a little poor with this catalyst system.

\section{Conclusion}

To improve the selectivity of Fenton reagent $\left(\mathrm{Fe}^{2+} / \mathrm{H}_{2} \mathrm{O}_{2}\right)$ in oxidation reaction, the cooperation between Fenton reagent and a series of additives has been investigated. It was found that the reactivity and selectivity of Fenton system were improved with NHPI as cocatalyst. The oxidation of benzyl alcohol catalyzed by this new $\mathrm{Fe}^{2+} / \mathrm{H}_{2} \mathrm{O}_{2} /$ NHPI system can be well performed under room temperature without adding any organic solvent. Besides, this catalyst system is effective for the oxidation of different alcohols. We hope the catalyst systems developed here provide a new way for a green, innoxious, and cheap candidate for the oxidation of alcohols and similar compounds.

\section{Conflict of Interests}

The authors declare that they have no conflict of interests regarding the publication of this paper.

\section{Acknowledgment}

This work was supported by the National Natural Science Foundation of China (no. 21176110).

\section{References}

[1] H. R. Eisenhauer, "Oxidation of phenolic wastes," Journal (Water Pollution Control Federation), vol. 36, no. 9, pp.1116-1128, 1964.

[2] J. H. Ramirez, F. M. Duarte, F. G. Martins, C. A. Costa, and L. M. Madeira, "Modelling of the synthetic dye Orange II degradation using Fenton's reagent: from batch to continuous reactor operation," Chemical Engineering Journal, vol. 148, no. 2-3, pp. 394-404, 2009.

[3] J. A. Zazo, J. A. Casas, A. F. Mohedano, M. A. Gilarranz, and J. J. Rodríguez, "Chemical pathway and kinetics of phenol oxidation by Fenton's reagent," Environmental Science and Technology, vol. 39, no. 23, pp. 9295-9302, 2005.

[4] H. Y. Wang, Y. N. Hu, G. P. Cao, and W. K. Yuan, "Degradation of propylene glycol wastewater by Fenton's reagent in a semicontinuous reactor," Chemical Engineering Journal, vol. 170, no. 1, pp. 75-81, 2011.
[5] F. Haber and J. Weiss, "The catalytic decomposition of hydrogen peroxide by iron salts," Proceedings of the Royal Society A, vol. 147, pp. 332-351, 1934.

[6] J. Weiss, "Investigations on the radical $\mathrm{HO}_{2}$ in solution," Transactions of the Faraday Society, vol. 31, pp. 668-681, 1995.

[7] A. Santos, P. Yustos, S. Rodríguez, and A. Romero, "Mineralization lumping kinetic model for abatement of organic pollutants using Fenton's reagent," Catalysis Today, vol. 151, no. 1-2, pp. 8993, 2010.

[8] M. S. Lucas, A. A. Dias, A. Sampaio, C. Amaral, and J. A. Peres, "Degradation of a textile reactive Azo dye by a combined chemical-biological process: fenton's reagent-yeast," Water Research, vol. 41, no. 5, pp. 1103-1109, 2007.

[9] D. Mantzavinos and E. Psillakis, "Enhancement of biodegradability of industrial wastewaters by chemical oxidation pretreatment," Journal of Chemical Technology and Biotechnology, vol. 79, no. 5, pp. 431-454, 2004.

[10] F. Gozzo, "Radical and non-radical chemistry of the Fentonlike systems in the presence of organic substrates," Journal of Molecular Catalysis A: Chemical, vol. 171, no. 1-2, pp. 1-22, 2001.

[11] C. Espro, S. Marini, F. Mendolia, F. Frusteri, and A. Parmaliana, "Enhancing effect of S and F moieties on the performance of Fenton system in the selective oxidation of propane," Catalysis Today, vol. 141, no. 3-4, pp. 306-310, 2009.

[12] W. Wang, M. H. Zhou, Q. Mao, and X. Wang, "Novel NaY zeolite-supported nanoscale zero-valent iron as an efficient heterogeneous Fenton catalyst," Catalysis Communications, vol. 11, no. 11, pp. 937-941, 2010.

[13] F. Shi, M. K. Tse, Z. Li, and M. Beller, "Controlling ironcatalyzed oxidation reactions: from non-selective radical to selective non-radical reactions," Chemistry, vol. 14, no. 29, pp. 8793-8797, 2008.

[14] M. P. Ormad, R. Mosteo, C. Ibarz, and J. L. Ovelleiro, "Multivariate approach to the photo-Fenton process applied to the degradation of winery wastewaters," Applied Catalysis B: Environmental, vol. 66, no. 1-2, pp. 58-63, 2006.

[15] J. de Laat and T. G. Le, "Effects of chloride ions on the iron(III)-catalyzed decomposition of hydrogen peroxide and on the efficiency of the Fenton-like oxidation process," Applied Catalysis B: Environmental, vol. 66, no. 1-2, pp. 137-146, 2006.

[16] C. K. Duesterberg, W. J. Cooper, and T. D. Waite, "Fentonmediated oxidation in the presence and absence of oxygen," Environmental Science and Technology, vol. 39, no. 13, pp. 50525058, 2005.

[17] J. J. Pignatello, E. Oliveros, and A. Mackay, "Advanced oxidation processes for organic contaminant destruction based on the fenton reaction and related chemistry," Critical Reviews in Environmental Science and Technology, vol. 36, no. 1, pp. 1-84, 2006.

[18] P. Bautista, A. F. Mohedano, J. A. Casas, J. A. Zazo, and J. J. Rodriguez, "An overview of the application of Fenton oxidation to industrial wastewaters treatment," Journal of Chemical Technology and Biotechnology, vol. 83, no. 10, pp. 1323-1338, 2008.

[19] W. Manchot, "Ueber Sauerstoffactivirung," Liebigs Annalen Der Chemie, vol. 314, no. 1-2, pp. 177-199, 1901.

[20] K. V. Padoley, S. N. Mudliar, S. K. Banerjee, S. C. Deshmukh, and R. A. Pandey, "Fenton oxidation: a pretreatment option for improved biological treatment of pyridine and 3-cyanopyridine plant wastewater," Chemical Engineering Journal, vol. 166, no. 1, pp. 1-9, 2011. 
[21] H. G. William, L. Yiishyan, and J. W. Kang, "Advanced oxidation processes. A kinetic model for the oxidation of 1,2-dibromo3 -chloropropane in water by the combination of hydrogen peroxide and UV radiation," Industrial \& Engineering Chemistry Research, vol. 34, no. 7, pp. 2314-2323, 1995.

[22] M. C. Lu, Y. F. Chang, Y. M. Chen, and Y. Y. Huang, "Effect of chloride ions on the oxidation of aniline by Fenton's reagent," Journal of Environmental Management, vol. 75, no. 2, pp. 177$182,2005$.

[23] M.-C. Lu, J.-N. Chen, and C.-P. Chang, "Effect of inorganic ions on the oxidation of dichlorvos insecticide with Fenton's reagent," Chemosphere, vol. 35, no. 10, pp. 2285-2293, 1997.

[24] X. B. Hu, J. Y. Mao, Y. Sun, H. Chen, and H. R. Li, "Acetylacetone-Fe catalyst modified by imidazole ionic compound and its application in aerobic oxidation of $\beta$-isophorone," Catalysis Communications, vol. 10, no. 14, pp. 1908-1912, 2009.

[25] W. H. Guan, C. M. Wang, X. Yun, X. B. Hu, Y. Wang, and H. R. Li, "A mild and efficient oxidation of 2,3,6-trimethylphenol to trimethyl-1,4-benzoquinone in ionic liquids," Catalysis Communications, vol. 9, no. 10, pp. 1979-1981, 2008.

[26] M. Rong, C. Liu, J. Han, and H. Wang, "Catalytic oxidation of alcohols by a double functional ionic liquid [bmim] $\mathrm{BF}_{4}$," Catalysis Communications, vol. 10, no. 4, pp. 362-364, 2009.

[27] U. K. Sharma, N. Sharma, R. Kumar, R. Kumar, and A. K. Sinha, "Biocatalytic promiscuity of lipase in chemoselective oxidation of aryl alcohols/acetates: a unique synergism of calb and [hmim]br for the metal-free $\mathrm{H}_{2} \mathrm{O}_{2}$ activation," Organic Letters, vol. 11, no. 21, pp. 4846-4848, 2009.

[28] I. Casero, D. Sicilia, S. Rubio, and D. Pérez-Bendito, "Chemical degradation of aromatic amines by Fenton's reagent," Water Research, vol. 31, no. 8, pp. 1985-1995, 1997.

[29] M. C. Lu, J. N. Chen, and C. P. Chang, "Oxidation of dichlorvos with hydrogen peroxide using ferrous ion as catalyst," Journal of Hazardous Materials B, vol. 65, pp. 277-288, 1999.

[30] J. J. Pignatello and Dark a, "nd photoassisted iron(3+)-catalyzed degradation of chlorophenoxy herbicides by hydrogen peroxide," Environmental Science \& Technology, vol. 26, no. 5, pp. 944951, 1992.

[31] D. Bianchi, R. Bortolo, R. Tassinari, M. Ricci, and R. Vignola, "A novel iron-based catalyst for the biphasic oxidation of benzene to phenol with hydrogen peroxide," Angewandte Chemie, vol. 112, no. 23, pp. 4491-4493, 2000.

[32] Z. Yao, X. Hu, J. Mao, and H. Li, "An environmentally benign catalytic oxidation of cholesteryl acetate with molecular oxygen by using N-hydroxyphthalimide," Green Chemistry, vol. 11, no. 12, pp. 2013-2017, 2009.

[33] T. Hara, T. Iwahama, S. Sakaguchi, and Y. Ishii, "Catalytic oxyalkylation of alkenes with alkanes and molecular oxygen via a radical process using N-hydroxyphthalimide," Journal of Organic Chemistry, vol. 66, no. 19, pp. 6425-6431, 2001.

[34] Y. Aoki, S. Sakaguchi, and Y. Ishii, "synthesis of naphthalenediols by aerobic oxidation of diisopropylnaphthalenes catalyzed by N-hydroxyphthalimide (NHPI)/ $\alpha, \alpha^{\prime}$-azobisisobutyronitrile (AIBN)," Advanced Synthesis \& Catalysis, vol. 346, no. 2-3, pp. 199-202, 2004.

[35] Y. Ishii, S. Sakaguchi, and T. Iwahama, "Innovation of hydrocarbon oxidation with molecular oxygen and related reactions," Advanced Synthesis and Catalysis, vol. 343, no. 5, pp. 393-427, 2001. 

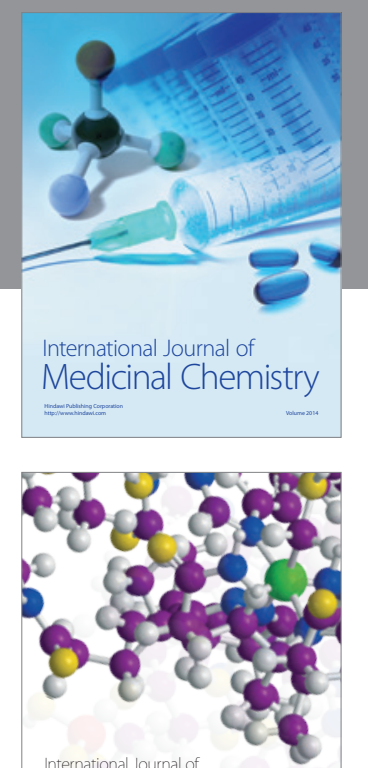

\section{Carbohydrate} Chemistry

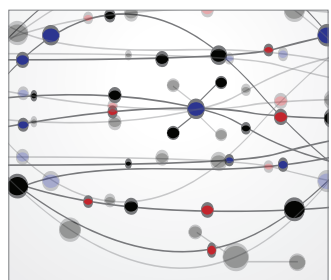

The Scientific World Journal
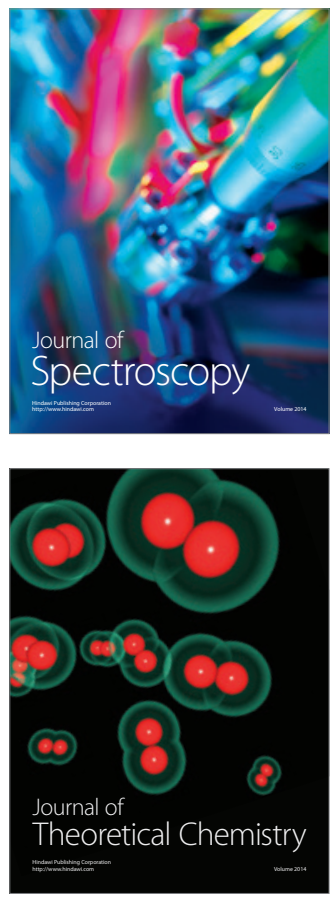
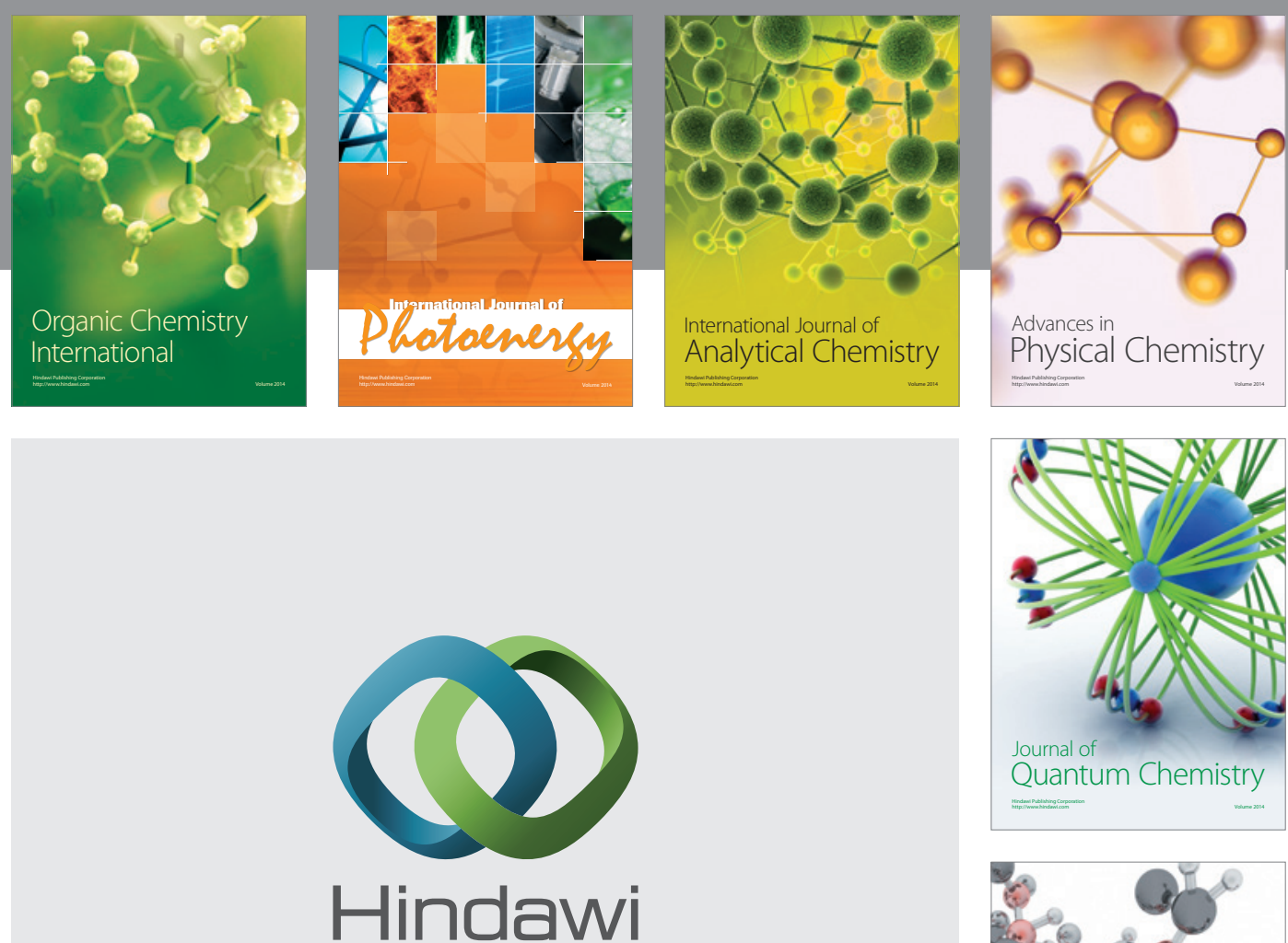

Submit your manuscripts at

http://www.hindawi.com

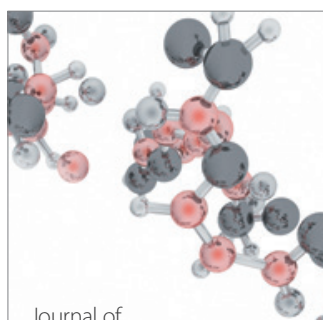

Analytical Methods

in Chemistry

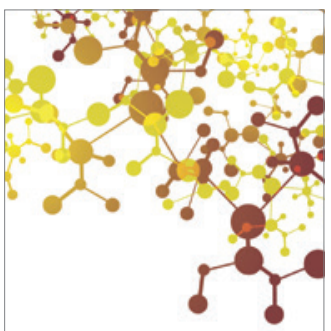

Journal of

Applied Chemistry

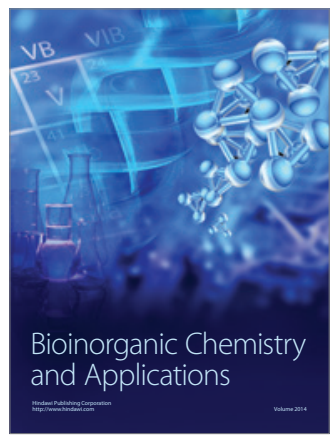

Inorganic Chemistry
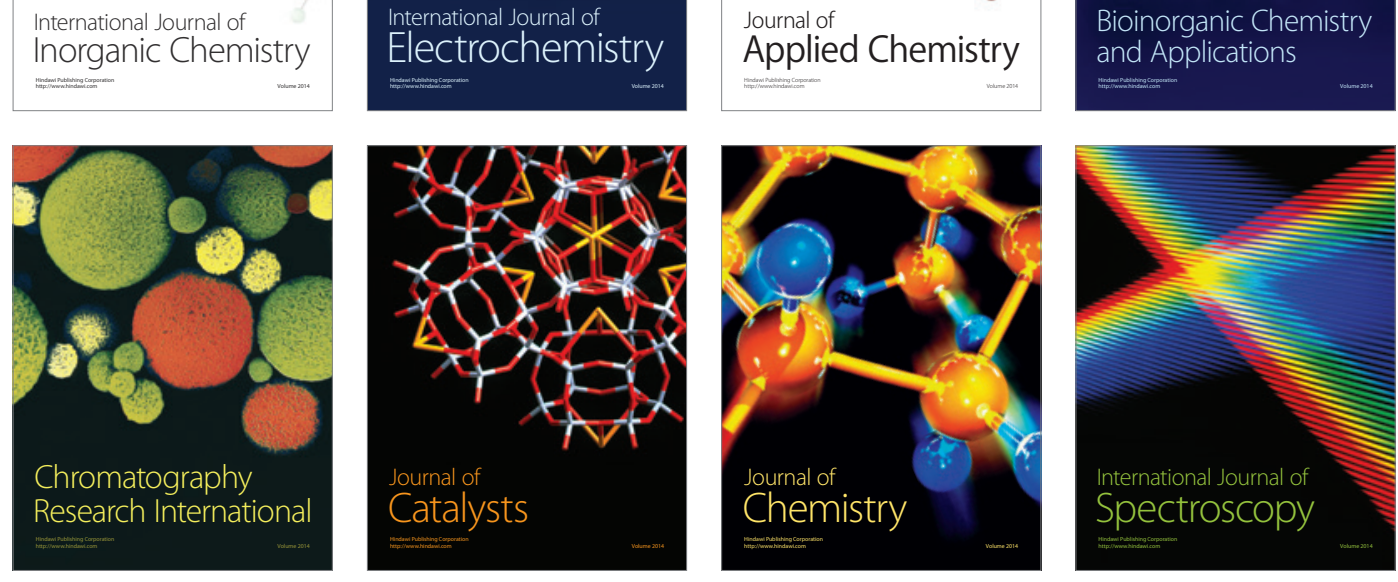